\title{
Kırmızı Soğandan Karbon Kuantum Noktaların Sentezi ve Fotolüminesans Özelliklerinin İncelenmesi
}

\author{
Abdullah BİÇER*1 ${ }^{*}$, Kübra BİLMişoĞLU BİÇER ${ }^{2} \oplus$ \\ ${ }^{1}$ Akdeniz Üniversitesi, Fen Fakültesi, Kimya Bölümü, 07058, Antalya, Türkiye \\ ${ }^{2}$ Atatürk Üniversitesi, Fen Fakültesi, Kimya Bölümü, 25240, Erzurum, Türkiye
}

(Alınış / Received: 26.05.2019, Kabul / Accepted: 21.01.2020, Online Yayınlanma / Published Online: 20.04.2020)

Anahtar Kelimeler

Karbon kuantum noktalar, Fotolüminesans,

Absorpsiyon,

Floresans
Özet: Bu çalışmada doğal materyal olan kırmızı soğandan karbon kuantum noktaları sentezlendi. Karbon kuantum noktaların yapısı XRD ve FTIR spektrumları ile belirlendi. Boyut ve yüzey yükü analizleri yapıldı. Karakterizasyonu yapılan karbon kuantum noktaların fotofiziksel özellikleri araştırıldı. Daha sonra fotofiziksel özellikleri üzerine konsantrasyon, $\mathrm{pH}$ ve sıcaklığın etkisi incelendi. Konsantrasyon çalışmaları ile uygun çözeltinin 250 $\mu \mathrm{l} / 4950 \mu \mathrm{l}$ saf su karışımı olduğu belirlendi. Bu konsantrasyonda yapılan $\mathrm{pH}$ çalışması ile karbon kuantum noktanın pH değeri ve sıcaklık arttıkça floresans özelliğinin azaldığı ve uzun zaman aralığında (3 ay) kararlılığını koruduğu gözlendi.

\section{Synthesis of Carbon Quantum Dots from Red Onions and Analysis of Photoluminescence Properties}

\section{Keywords}

Karbon quantum dots,

Photoluminescence,

Absorption,

Fluorescence

\begin{abstract}
In this study, carbon quantum dots were synthesized from a natural material which is red onion. Structure of carbon quantum dots was determined by XRD and FTIR spectra. Analysis of size and surface load was performed. The photophysical properties of characterized carbon quantum dots were investigated. Then, the effect of concentration, $\mathrm{pH}$ and temperature on the photophysical properties of the carbon quantum dots sample was investigated. Concentration studies indicated that the appropriate solution was a mixture of $250 \mu \mathrm{l} / 4950 \mu \mathrm{l}$ pure water. With the $\mathrm{pH}$ study performed at this concentration, it was observed that fluorescence feature decrease as $\mathrm{pH}$ value and temperature increases of the carbon quantum dots and it maintained its stability over a long period of time (3 months).
\end{abstract}

\section{Giriş}

Karbon nano noktalar, floresans nanopartiküllerin en yeni sınıfını oluşturmakta olup kuantum nokta ailesinin yeni üyesi olarak görülmektedir [1]. Karbon nanonoktalar ilk defa preperatif elektroforez ile tek duvarlı karbon nanotüplerin saflaştırılmasıyla [2] ve daha sonra grafitin lazer ablasyonu ile elde edilmiştir [3]. Karbon kuantum noktalar yüzeyinde çok fazla fonksiyonel gruplar bulunan, karbonizasyon derecesi değiştirilebilen karbon materyalidir. Karbon noktalar optik ve kimyasal özeliklerinden dolayı çok büyük ilgi görmekte ve elekrokataliz, biyo-görüntüleme, kimyasal-sensör, biyo-sensör, nanomedikal, biyomolekül/ilaç salınımı, ışık saçan diyotlar, fotokatalizör olarak geniş bir kullanım alanına sahiptir [4-7]. Ayrıca lazerler, optoelektronik araç uygulamaları gibi alanlarda da umut verici uygulamaları bulunmaktadır $[8,9]$.
Karbon kuantum noktaların sentezinde farklı çıkış bileşikleri ve yöntemlerle yaplabilmektedir. Son zamanlarda karbon nokta yapılarının sentezinde doğal materyallerin kullanımı yaygındır. Doğal karbon kaynağı olarak pek çok bitki, meyve ve farklı organik materyaller kullanılabilmektedir. Bu organik materyallerden elde edilen kuantum verimleri Tablo 1 'de gösterilmiştir.

Karbon kuantum noktalar, geleneksel yarı iletken kuantum noktaların yerine aday gösterilmekte ve düşük toksisite, kimyasal inertlik, suda çözünebilme, biyouyumluluk, kolay fonksiyonelleştirme ve çeşitli fotolüminesans özeliklerinden dolayı gelecekte nanoaraç uygulamalarında kullanım alanına sahip olacağı düşünülmektedir $[10,11]$. 
Tablo 1. Doğal materyallerden elde edilen karbon noktaların kuantum verim karșlaștırması

\begin{tabular}{|c|c|c|}
\hline Karbon Kaynağı & $\begin{array}{c}\text { Kuantum } \\
\text { verimi }\end{array}$ & Referans \\
\hline İnek Gübresi & 65 & [19] \\
\hline Jinhua Bergamot & 50,78 & [19] \\
\hline İpek Kozası & 38 & [19] \\
\hline Atık Portakal Kabuğu & 36 & [27] \\
\hline Jelâtin & 31,6 & [21] \\
\hline Elma Suyu & 26 & [19] \\
\hline Portakal Suyu & 26 & [17] \\
\hline Bal & 19,8 & [19] \\
\hline Karides Yumurtası & 18,5 & [19] \\
\hline Sarımsak & 17,5 & [19] \\
\hline Lahana & 16,5 & [19] \\
\hline Yumurta Kabuğu & 14 & [19] \\
\hline $\begin{array}{l}\text { İpek Böceğinden Elde } \\
\text { Edilen İpek }\end{array}$ & 13,9 & [13] \\
\hline Konjak Unu & 13 & [19] \\
\hline Soya Fasülyesi & 13 & [19] \\
\hline Arı Polenleri & 12,8 & [19] \\
\hline Süt & 12 & [23] \\
\hline Saç & 11,1 & [28] \\
\hline Aloe Yaprağl & 10,37 & [14] \\
\hline Liçi (Lychee) Tohumu & 10,6 & [19] \\
\hline Fistık Kabuğu & 9,91 & {$[20]$} \\
\hline Yumurta & 8 & {$[28]$} \\
\hline Kıș Kavunu & 7,51 & [12] \\
\hline Karpuz Kabuğu & 7,1 & [19] \\
\hline Pomela Kabuğu & 6,9 & [5] \\
\hline Çilek Suyu & 6,3 & [7] \\
\hline Çimen & 6,2 & [29] \\
\hline Patates & 6,14 & [19] \\
\hline Söğüt Ağacı Kabuğu & 6 & [26] \\
\hline Şeker Kamıșı Suyu & 5,76 & [28] \\
\hline Nescafe Kahvesi & 5,5 & [19] \\
\hline Un & 5,4 & [26] \\
\hline Ekmek & 4,5 & [19] \\
\hline Muz Suyu & 4,27 & [19] \\
\hline Mango & 3,92 & [19] \\
\hline Kahve Telvesi & 3,8 & [19] \\
\hline Tütün & 3,2 & [19] \\
\hline Üzüm Yaprağı & 3,1 & [19] \\
\hline Tatlı Patetes & 2,8 & [19] \\
\hline Soya Sütü & 2,6 & [24] \\
\hline Arap Sakızı (Gam arabic) & 0,9 & [18] \\
\hline Mum Kurumu & 0,51 & [25] \\
\hline Kandil İsi & 0,019 & [15] \\
\hline
\end{tabular}

\section{Materyal ve Metot}

Deneysel çalışmalarda kullanılan kırmızı kuru soğan yerel marketten temin edilmiştir. Sentezlenen karbon kuantum noktaların yapısal özellikleri PANalytical Empyrean X-Ray Difraktometresi ile, yüzeyindeki fonksiyonel gruplar Mattson 1000 FTIR Spektrometresi ile, partikül boyutu ve yüzey yükü Zetasizer Nano Series cihazı ile belirlendi.

Absorpsiyon ölçüleri Perkin Elmer Lambda 35 UV/VIS Spektrometre ile,floresans yaşam ömrü PTI TM3 Time Master Spektroflorimetre ile ve floresans kuantum verimi Shimadzu RF-5301 PC Spektroflorimetresi ile elde edildi.

\subsection{Karbon kuantum noktaların sentezi}

Sentez için yerel pazardan temin edilen kırmızı renkli soğanlar kabuklarıyla birlikte rondodan geçirildi. 50 gram kırmızı soğan sıvı azot ile birlikte dövüldü ve 50 ml su ilavesi ile 8 saat $133{ }^{\circ} \mathrm{C}$ otoklavda bekletildi, sonrasında otoklavdan alınan madde süzülerek, 0.22 $\mu \mathrm{m}$ inceliğindeki membrandan geçirilerek stok çözeltileri hazırlandı[29,30].

Hazırlanan karbon kuantum noktaların, floresans kuantum verimleri ( $\left.\Phi_{\mathrm{f}}\right)$ Parker-Rees metoduyla belirlendi. Bu metodun en önemli özelliği, fotofiziksel özelliği iyi belirlenmiş bir floresans bileşiğe göre kuantum verimlerinin belirlenmesidir. Parker-Rees denklemi (1) de gösterilmiştir.

$$
\Phi_{S}=\Phi_{r}\left(D_{s} / D_{r}\right)\left(n_{s}^{2} / n_{r}^{2}\right)\left[\left(1-10^{-O D r} / 1-10^{-O D s}\right)\right]
$$

Burada $\Phi_{\mathrm{s}}$ ve $\Phi_{\mathrm{r}}$ sirasiyla, numune ve referansın floresans kuantum verimi; $D_{s}$ ve $D_{r}$, sirasiyla numune ve referansın düzeltilmiş floresans spektrumu altındaki alanları; $n_{s}$ ve $n_{r}$ sirasıyla numune ve referansın çözücüsünün kırılma indisi; $\mathrm{OD}_{\mathrm{s}}$ ve $\mathrm{OD}_{\mathrm{r}}$, sırasıyla numune ve referansın uyarılma dalga boyunda ölçülen optik yoğunluğudur [31].

Karbon kuantum nokta numunelerinin floresans yaşam ömrü, stroboskopik dedektörle çalışan Time Master Laser sistemi ile belirlenmiştir. Floresans yașam ömrü, bir bileșiğin veya ilgilenilen türün uyarılmış elektronik hallerde harcadığı zaman şeklinde tanımlanır. Floresans yaşam ömrü denklem (2) de gösterilmiştir.

$$
\tau_{f}=\frac{1}{k_{I C}+k_{I S C}+k_{r}}
$$

Burada; $\tau_{\mathrm{f}}$ floresans yaşam ömrü, $\mathrm{k}_{\mathrm{IC}}$ iç dönüşüm olayının hız sabiti, kısc sistemler arası geçiş olayının hız sabiti ve $k_{r}$ radyasyonlu geçişler için hız sabitidir. Karbon kuantum noktaların partikül boyutu için hacme dayalı hesaplanan sonuçlar kullanılarak partikülün şekli küre kabul edilip tane boyutu hidrodinamik çap olarak verilmiştir. Ölçümler Zetasizer cihazında $25^{\circ} \mathrm{C}$ sıcaklıkta, üç kez tekrarlanmıştır. Sonuçlar ölçümlerin ortalaması şeklinde verilmiştir [32].

\section{Bulgular}

Kırmızı renkli soğanlardan elde edilen numunelerde, karbon kuantum noktaların varlığını kanıtlamak amacıyla XRD spektrumu alındı (Şekil 1). XRD spektrumunda oldukça sıradan biçimde amorf karbon dizilimiyle ilgili olarak $\sim 20^{\circ}$ ve $\sim 38^{\circ}$ de iki 
geniş pik bulunmaktadır. Merkezi geniş bir pikin görülmesi karbon kuantum nokta yapısının varlığını göstermektedir. Karbon kuantum noktaların zayıf kristal yapısı, daha fazla oksijen içeren fonksiyonel grupların varlı̆̆ını göstermektedir.

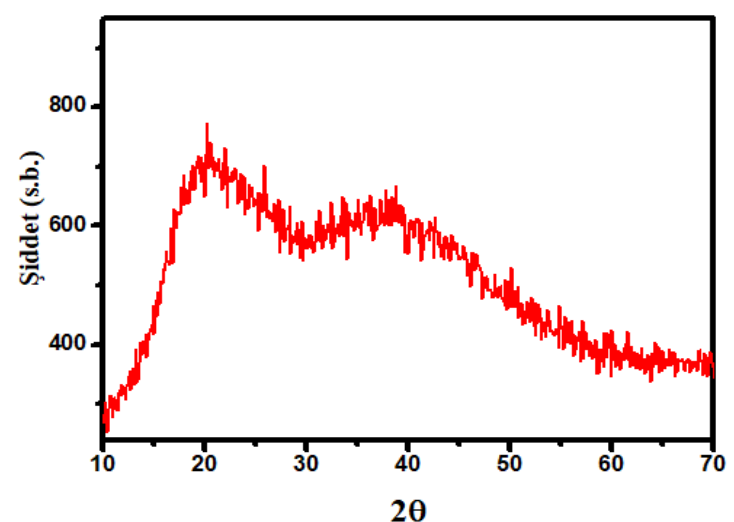

Şekil 1. Karbon kuantum nokta yapısının XRD spektrumu

Karbon kuantum nokta yüzeyindeki fonksiyonel grupları belirlenmek için FTIR analizi yapıldı. Bu amaçla hazırlanan karbon kuantum nokta numunesi etüvde 4 gün bekletilerek tamamen kurutuldu ve $\mathrm{KBr}$ ile peleti hazırlanarak ölçümü alındı (Şekil 2). FTIR spektrumunda $3237-3550 \mathrm{~cm}^{-1}$ arasında $\mathrm{O}-\mathrm{H}$ ve $\mathrm{N}-\mathrm{H}$, $3237 \mathrm{~cm}^{-1}$ de aromatik C-H, $1638 \mathrm{~cm}^{-1}$ 'de C-O-N, 1616 $\mathrm{cm}^{-1}$ 'de $\mathrm{C}=\mathrm{C}, 1078 \mathrm{~cm}^{-1}$ 'de C-O-C ve $619 \mathrm{~cm}^{-1}$ 'de ise C$\mathrm{X}$ gerilme titreşimleri gözlenmiştir. $\mathrm{Bu}$ gerilme titreșimlerinden, karbon kuantum noktaların yüzeyinde $-\mathrm{OH},-\mathrm{NH}$ ve $\mathrm{C}$-X gruplarının olduğu görülmekte olup su içerisinde çözünürlüğünün de yüksek olması ile biyomolekülleri bağlanması için bağlayıcı (linker) olarak kullanılabileceği belirlenmiștir.

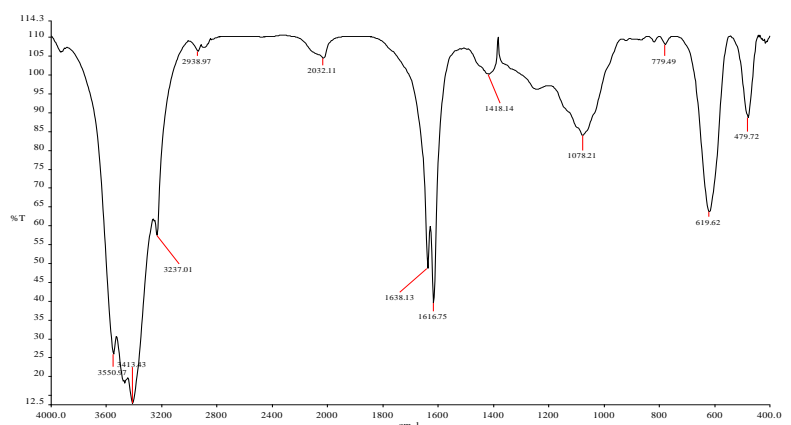

Şekil 2. Karbon kuantum nokta yapısının FTIR spektrumu

$250 \mu \mathrm{l}$ karbon nokta/4950 $\mu \mathrm{l}$ saf su olacak şekilde hazırlanan ve pH değeri 4,85 olarak ölçülen karbon kuantum nokta numunelerinin ortalama partikül boyut ölçümleri oda sıcaklıkğında üç kez tekrarlanmıștır. Sonuçlar ölçümlerin ortalaması şeklinde Şekil 3 ve Şekil 4'te verilmiştir. Parafilm referans alınarak (karbon içeriği en fazla olan referans olduğu için seçilmiştir) yapılan ölçümde partikül boyutu $8,21 \mathrm{~nm}$ olarak belirlenmiștir. Partikül boyutu genellikle $10 \mathrm{~nm}$ altında olduğundan bulunan bu değer literatürle oldukça uyumludur [4].

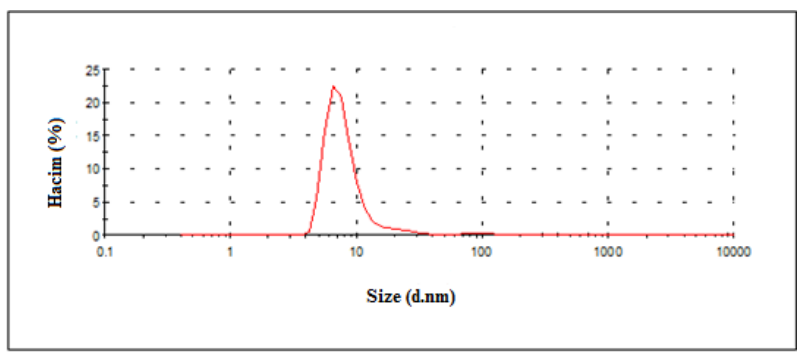

Şekil 3. Karbon kuantum nokta yapılarının partikül boyut grafiği

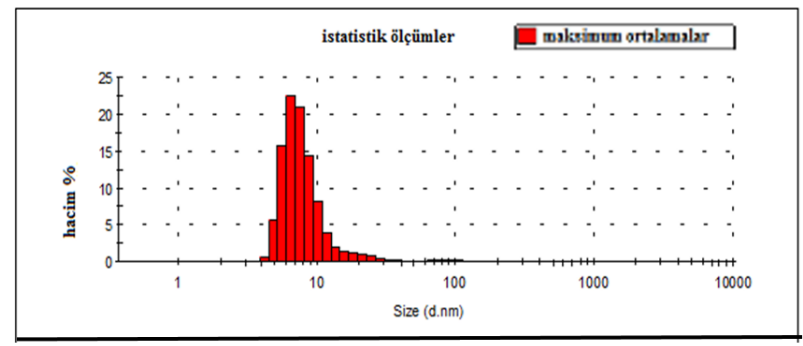

Şekil 4. Karbon kuantum nokta yapılarının partikül ölçümü istatistikleri

Zeta potansiyeli, molekülün etrafındaki elektriksel çift tabaka sonucu oluşan yüklerden meydana gelmektedir. Elektriksel çift tabaka taneciklerin birbirini itmesine sebep olur ve böylece taneciklerin bir araya gelerek çökelmesini önler. Böylece zeta potansiyelinin yüksek olması sistemin kararlığına önemli katkı sağlamaktadır [32].

Sentezlenen karbon noktaların yüzey yüklerinin belirlenmesi zeta potansiyelinin hesaplanması ile gerçekleştirilmiştir. Zeta potansiyel değeri kararlı emülsiyon ve süspansiyon ölçümü için önem taşımaktadır. Zeta potansiyelinin $+25 \mathrm{mV}$ 'un üstünde veya -25 mV'un altında bulunduğu değerler emülsiyon ve süspansiyonların kararlı olduğu bölgeyi göstermektedir. Eğer bu değerler arasında değil ise kararsızdır ve böylelikle kolloidal sistemler topaklaşarak çökelme eğilimindedir [33]. Karbon nokta yapının zeta potansiyel değerleri Şekil 5'de verilmiștir. Karbon nokta yapının yüzey yükü Parafilm referans alınarak yapılan ölçümde -9,66 mV olarak bulunmuştur. Bu değer, +25 mV-(-25 mV) aralığında olup sentezlenen karbon nokta yapılarının kararlı olduğunu göstermektedir. Karbon nokta yapıların yüzeyindeki $\mathrm{NH}_{2}$ ve $\mathrm{OH}$ gruplarından dolayı negatif yük oluşmaktadır [5].

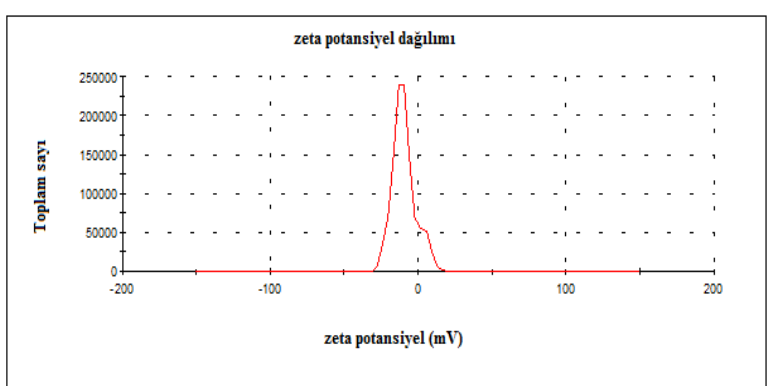

Şekil 5. Karbon kuantum nokta yapılarının zeta potansiyeli dağılım grafiği 
Karbon kuantum nokta yapısının (250 $\mu \mathrm{l}$ karbon kuantum nokta/4950 $\mu$ l saf su) zeta potansiyeline pH'nın etkisi incelenmiştir (Şekil 6). pH 2,80-11,00 aralığında değiştirildiğinde zeta potansiyel yükünün 9,64 mV'tan -19 mV'a indiği gözlenmiştir. Karbon kuantum nokta numunesinin izoelektronik $\mathrm{pH}$ değerinin 3,76 olduğu görülmektedir. $\mathrm{pH}=3,76$ 'dan daha düşük değerlerde karbon kuantum nokta yüzeyinin pozitif, $\mathrm{pH}=3,76$ 'dan daha büyük değerlerde ise yüzeyinin negatif yüklü olduğu tespit edilmiștir. Bu durum zeta potansiyeli değișimi ile karbon kuantum nokta yapısında protonlama ve deprotonlama mekanizmasının var olduğunu göstermektedir [13].

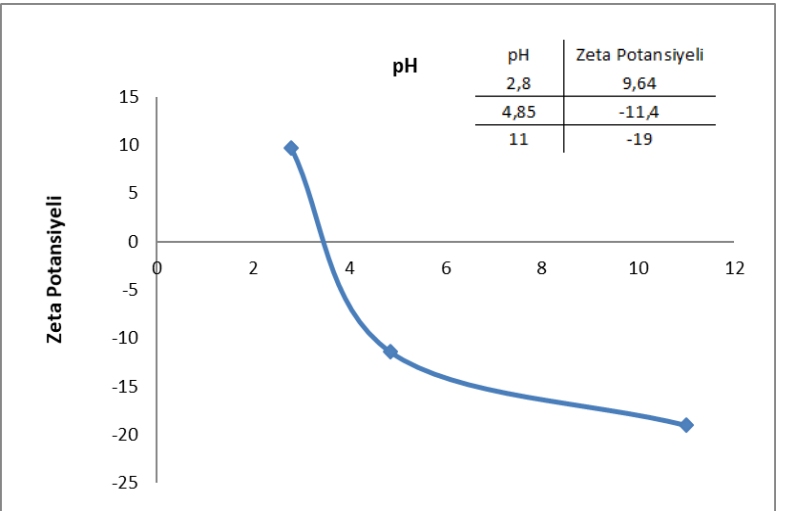

Şekil 6. Zeta potansiyeli ile $\mathrm{pH}$ arasındaki ilişki

Karbon kuantum nokta yapısının (250 $\mu \mathrm{l}$ karbon kuantum nokta/4950 $\mu \mathrm{l}$ saf su) $\mathrm{pH}$ (2.0-14.0) değerlerine karşı floresans şiddeti değişimi incelendiğinde $\mathrm{pH}$ 'ya bağlı olarak floresans şiddetinin azaldığı görülmektedir (Şekil 7). Bu durum karbon kuantum nokta yapısının yüzeyindeki fonksiyonel grupların deprotonlanmasından kaynaklanmaktadır [13].

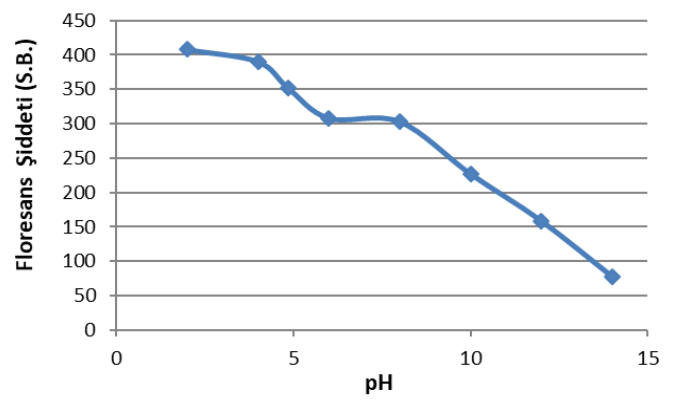

Şekil 7. Karbon kuantum noktanın floresans şiddetiyle $\mathrm{pH}$ ilişkisi

XRD ve FTIR ölçümleri ile yapısı aydınlatılan ve zeta potansiyeli ile boyutları ve yüzey yükü belirlenen karbon kuantum nokta numunesinin optiksel karakterizasyonu için oda sıcaklığında absorpsiyon spektrumları alınmıştır (Şekil 8). 280 nm'de $\pi-\pi$ * geçişlerinden kaynaklanan karakteristik karbon kuantum nokta piki gözlenmiştir. $\mathrm{Bu}$ durum elde edilen numunelerde karbon kuantum noktanın varlığını desteklemektedir [34].

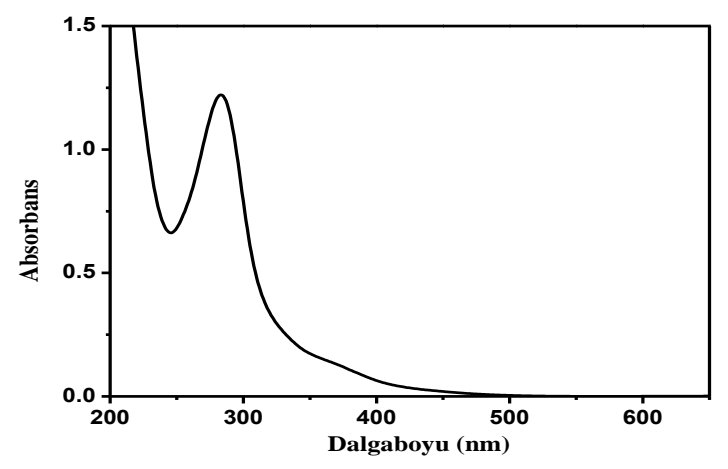

Şekil 8. Sentezlenen karbon kuantum nokta yapısının saf su içerisindeki absorpsiyon spektrumu

Absorpsiyon spektrumu belirlenen karbon kuantum nokta örneği için oda sıcaklığında farklı uyarma dalgaboylarında floresans ölçümleri alınmıştır (Şekil 9).
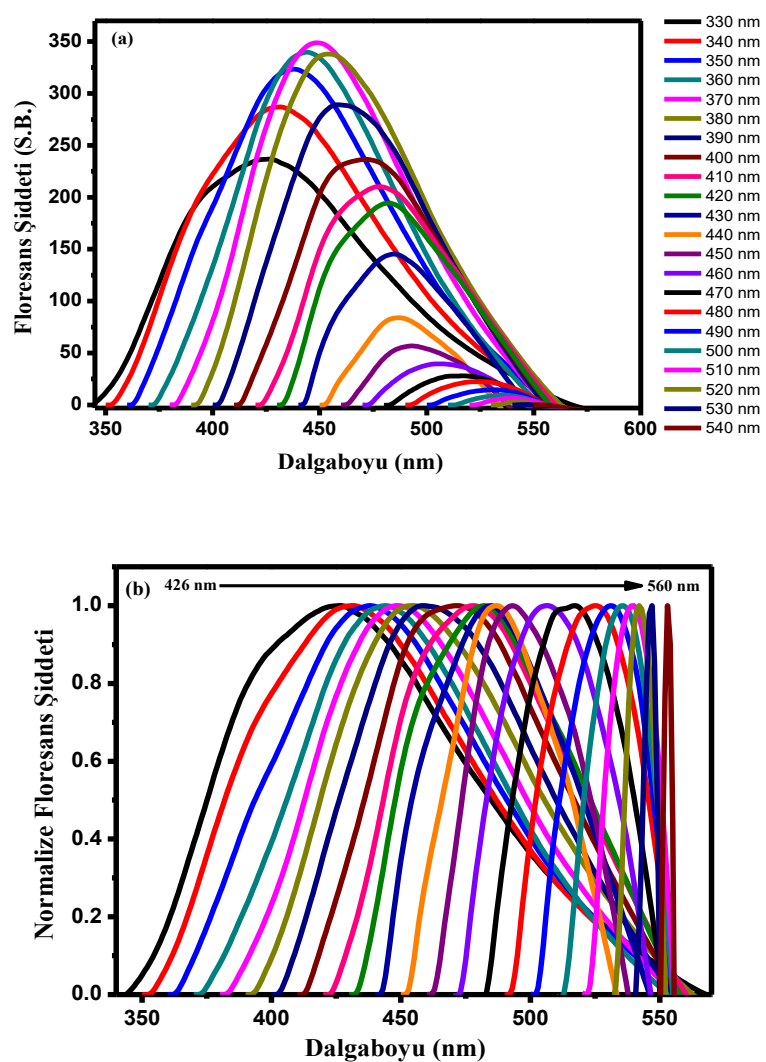

Şekil 9. Karbon kuantum nokta yapısının saf suda farklı dalga boylarındaki floresans spektrumları (a) ham (b) normalize.

Karbon kuantum noktaların su içerisinde farklı dalga boylarındaki floresans spekturumu Şekil 9'da gösterilmiştir. Uyarma dalgaboyunun $330 \mathrm{~nm}$ 'den 540 nm'ye (10'ar nm) kademeli olarak artırılmasıyla, floresans bant maksimumlarında 426 nm'den 560 nm'ye kırmızıya kaymalar gözlenmiştir (Şekil 9b). Uyarma dalgaboyları $340 \quad \mathrm{~nm}$ 'den $370 \quad \mathrm{~nm}$ 'ye artırıldığında floresans şiddetinde sürekli olarak bir artış, $380 \mathrm{~nm}$ ve sonrasında ise floresans şiddetinde bir azalma olduğu gözlenmiştir. Ayrıca, elde edilen 
karbon kuantum nokta için en şiddetli floresans pikinin $370 \mathrm{~nm}$ 'de olduğu görülmektedir. Uyarma dalgaboyu değiștirilerek floresans özelliğinin ayarlanabilir olması, partiküllerin yüzeydeki kusurları ve farklı boyutlardaki partiküllerin optik seçiminden kaynaklanabildiği bilinmektedir [35].

Elde edilen karbon kuantum noktaların sulu çözeltilerinin gün ışığı altında ve UV ışık altındaki görüntüleri Şekil 10'da verilmiştir. Karbon kuantum noktaların gün ışığında solgun sarı renkte ve UV ışığı altında parlak mavi floresans yaydığı, ayrıca karbon kuantum noktaların gün ışığında saydam olduğu görülmektedir.

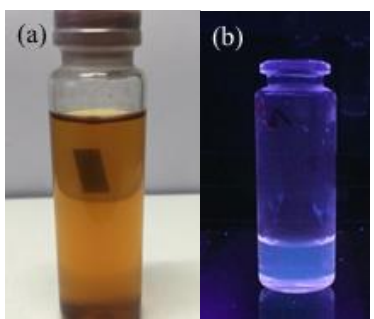

Şekil 10. Karbon kuantum nokta yapısının saf sudaki (a) gün ışığı (b) UV ışık altındaki görüntüsü.

Absorpsiyon ve floresans ölçümleri alınan kuantum nokta numunesi için fotofiziksel parametreler de hesaplandı. $350 \mathrm{~nm}$ uyarma dalgaboyunda alınan floresans spektrumuna ait alan kullanılarak (1) eşitliği yardımıyla kuantum nokta numunesinin floresans kuantum verimi ( $\Phi) 23$ ve floresans yaşam ömrü $(\tau)$ 2,582 ns olarak belirlenmiștir. Hesaplanan kuantum verimi, Tablo 1'de belirtilen farklı kaynaklardan elde edilen karbon kuantum nokta yapılarının kuantum verimleriyle kıyaslandığında kuantum veriminin oldukça iyi olduğu görülmektedir.

Absorpsiyon ve floresans spektrumları ile optik özellikleri belirlenen karbon kuantum nokta numunesi için spektral özellikler üzerine konsantrasyonun etkisi incelenmiştir. $\mathrm{Bu}$ amaçla hazırlanan stok çözeltiden 50-300 $\mu \mathrm{l}$ arasında değişen miktarlarda alınarak elde edilen yeni konsantrasyonlardaki çözeltilerin oda sıcaklığında absorpsiyon ve floresans ölçümleri alınmıștır (Şekil 11 ve Şekil 12).

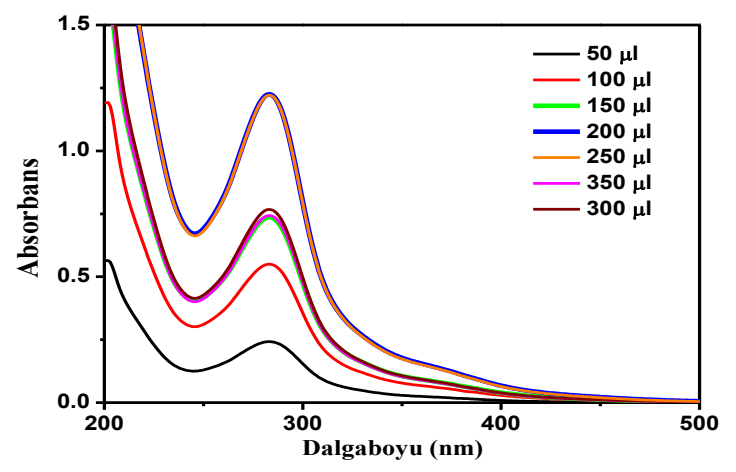

Şekil 11. Farklı konsantrasyonlardaki karbon kuantum nokta yapısının saf sudaki absorpsiyon spektrumları.

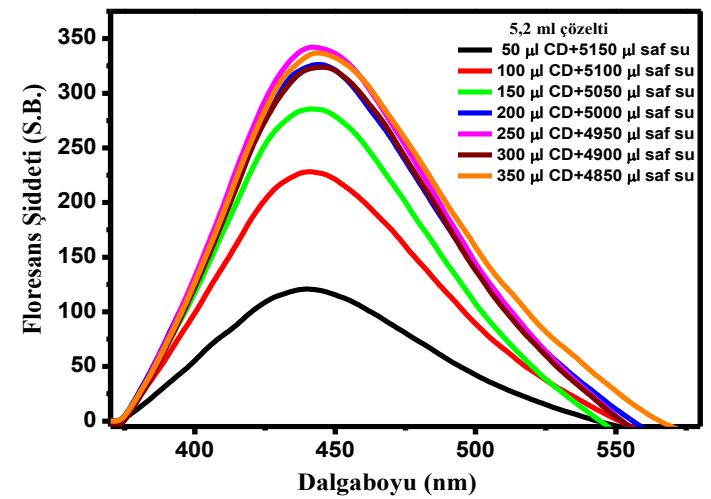

Şekil 12. Farklı konsantrasyonlardaki karbon kuantum nokta yapısının saf sudaki floresans spektrumları $\left(\lambda_{\mathrm{exc}}=360\right.$ $n m)$.

Şekil 12'de görüldüğü gibi tüm karbon nokta çözeltileri yaklaşık $440 \mathrm{~nm}$ emisyon dalga boyu civarında floresans göstermektedir. Ayrıca, karbon nokta miktarı arttıkça genel olarak floresans şiddetinin de arttığ gözlenmiştir.

Konsantrasyon çalışması sonucunda en iyi floresans özellik gösteren çözeltinin $250 \mu$ l karbon kuantum nokta/4950 $\mu$ l saf su karışımı olduğu belirlendikten sonra sistem üzerine pH'nın etkisi tartışılmıștır.

Asidik pH değerleri 0,1 M HCl çözeltisi ve bazik pH değerleri ise $0,1 \mathrm{M} \mathrm{NaOH}$ çözeltisi ile ayarlanmıştır. Bu ayarlamalar yapılmadan önce çözeltinin pH sı 4,85 olarak ölçülmüştür. Farklı pH aralıklarında $(\mathrm{pH}=2$ 14) çözelti için absorpsiyon ve floresans ölçümleri alınmıştır (Şekil 13 ve Şekil 14). Bu spektrumlarda görüldüğü gibi kırmızı soğandan elde edilen karbon nokta yapısıyla hazırlanan çözeltilerin asidik $\mathrm{pH}$ değerlerinde $(\mathrm{pH}=2-6)$ hem absorpsiyon hem de floresans şiddeti yüksekken bazik pH'lara doğru gidildikçe şiddetlerde azalmalar gözlenmiştir.

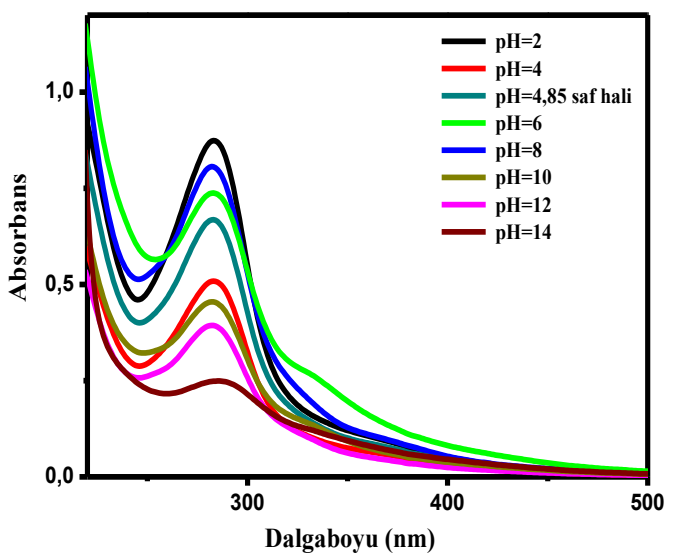

Şekil 13. $250 \mu \mathrm{l}$ karbon kuantum nokta/4950 $\mu \mathrm{l}$ saf su çözeltisinin farklı pH değerlerindeki absorpsiyon spektrumları. 


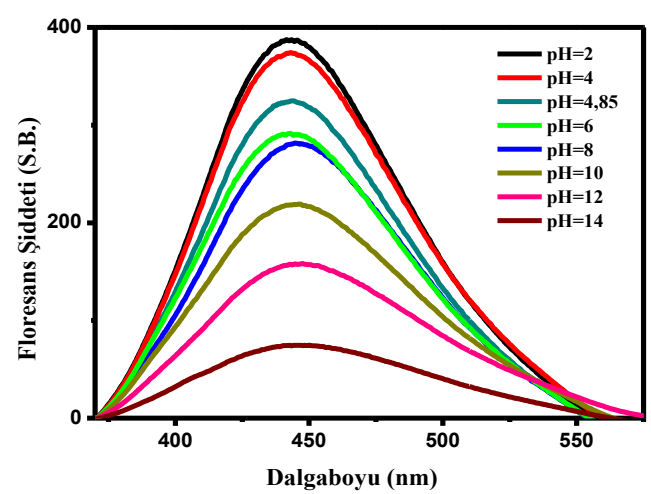

Şekil 14. $250 \mu \mathrm{l}$ karbon kuantum nokta/4950 $\mu \mathrm{l}$ saf su çözeltisinin farklı $\mathrm{pH}$ değerlerindeki floresans spektrumları $\left(\lambda_{\text {exc }}=360 \mathrm{~nm}\right)$.

Karbon nokta numunesinin fizyolojik pH'ya yakın değerlerde $(\mathrm{pH}=6)$ iyi bir foto stabiliteye sahip olması ve yüksek floresans emisyon göstermesi biyogörüntüleme uygulamalarında kullanılabilirliğini göstermektedir [35].

Farklı pH aralıklarında $(\mathrm{pH}=2-14)$ hazırlanan çözeltilerin gün ışığı ve UV ışık altındaki görüntüleri Şekil 15’de verilmiştir.

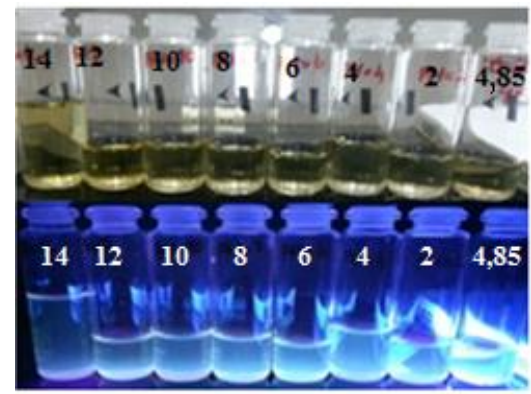

Şekil 15. $250 \mu \mathrm{l}$ karbon kuantum nokta/4950 $\mu \mathrm{l}$ saf su çözeltisinin farklı pH değerlerinde günışığı (üstte) ve UV ışık (altta) altındaki görünümleri

En iyi floresans özellik gösteren $250 \mu$ karbon kuantum nokta/4950 $\mu \mathrm{l}$ saf su karışımı üzerine sıcaklığın etkisi de incelenmiştir. Bu amaçla farklı sıcaklık aralıklarında $\left(0-100^{\circ} \mathrm{C}\right)$ çözelti için absorpsiyon ve floresans ölçümleri alınmıştır (Şekil 16 ve Şekil 17).

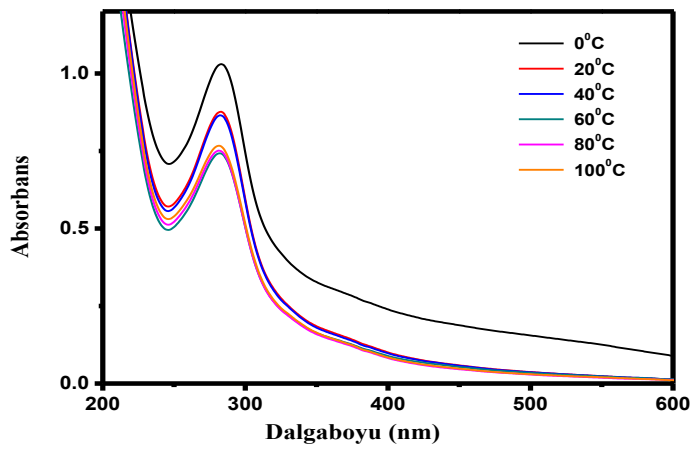

Şekil 16. $250 \mu \mathrm{l}$ karbon kuantum nokta/4950 $\mu \mathrm{l}$ saf su çözeltisinin farklı sıcaklıklardaki absorpsiyon spektrumları

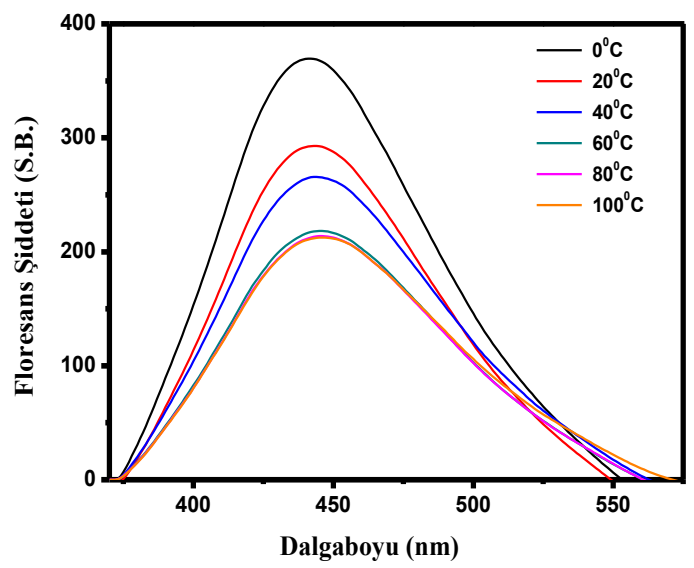

Şekil 17. $250 \mu \mathrm{l}$ karbon kuantum nokta/4950 $\mu \mathrm{l}$ saf su çözeltisinin farklı sıcaklıklardaki floresans spektrumları $\left(\lambda_{\text {exc }}=360 \mathrm{~nm}\right)$

Şekil 16'da görüldüğü gibi karbon kuantum nokta çözeltisinin absorpsiyon spektrumu sicaklık değişiminden oldukça az oranda etkilenmiştir. Bu durum karbon kuantum noktanın geniş bir sıcaklık aralığında dayanıklılığını göstermektedir. Tam tersi, karbon kuantum nokta çözeltisinin floresans şiddeti sıcaklığın artmasıyla azalmaktadır (Şekil 17). Bu durumun, sıcaklığın artmasıyla ışımasız geçişlerin artmasından kaynaklandığı düşünülmektedir [34].

Elde edilen karbon kuantum noktanın kararlılığını belirlemek amacıyla $18^{\circ} \mathrm{C}$ sıcaklıkta üç ay bekletilen numune için absorpsiyon ve floresans ölçümleri alındı (Şekil 18 ve Şekil 19). Absorpsiyon ve floresans spektrumlarında, kırmızı soğandan elde edilen karbon kuantum nokta numuneleri 3 ay gibi uzun bir süre bekletilmesine rağmen çok büyük bir değişim olmadığı görülmüştür. Bu durum ile elde edilen kuantum noktaların oldukça kararlı olduğu ve bu özellikleri ile uzun sürede gerçekleştirilmesi gereken çalışmalara büyük fayda sağlayacağı belirlenmiştir.

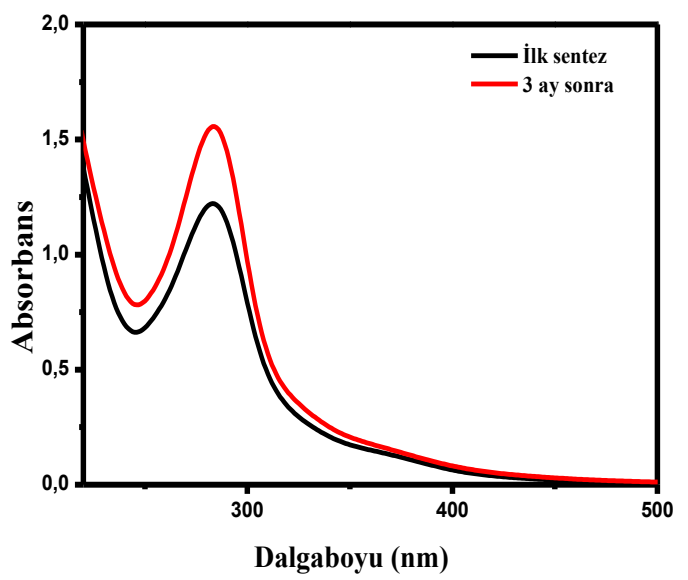

Şekil 18. Karbon kuantum nokta yapısının ilk ve 3 ay sonraki absorpsiyon spektrumu. 


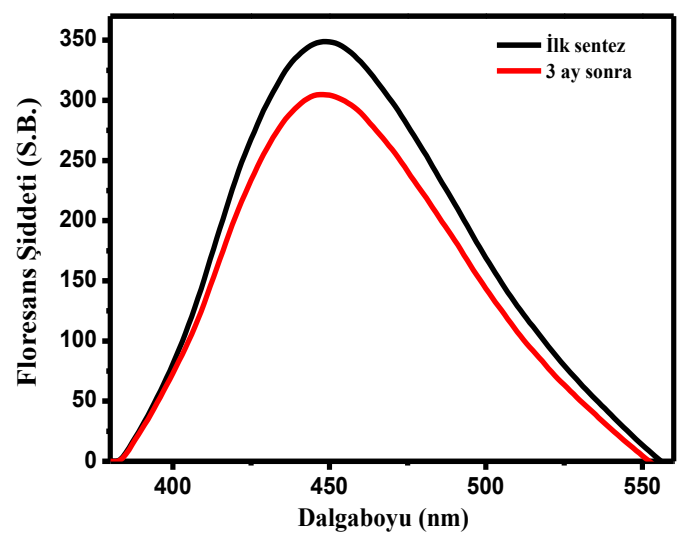

Şekil 19. Karbon kuantum nokta yapısının ilk ve 3 ay sonraki floresans spektrumu $\left(\lambda_{\mathrm{exc}}=370 \mathrm{~nm}\right)$.

\section{Tartışma ve Sonuç}

$\mathrm{Bu}$ çalışmada, doğal bir bitki olan kırmızı soğandan oldukça ekonomik ve pratik bir yolla karbon kuantum nokta numuneleri elde edilmiştir. Elde edilen bu numunelerin kuantum nokta yapısını kanıtlamak için XRD ve FTIR spektrumları alınmış ve bu spektrumlardan numunelerin karbon kuantum noktalar olduğu anlaşılmıștır. Ayrıca, bu numunelerin yüzey yükleri ve ortalama parçacık boyutları belirlenmiștir. Elde edilen sonuçlarla, karbon kuantum nokta numunelerinin ortalama parçacık boyutlarının $8,21 \mathrm{~nm}$ ve yüzey yüklerinin ise $-9,66$ $\mathrm{mV}$ olduğu bulunmuştur.

Yapısı kanitlanan bu numunelerin fotofiziksel özellikleri UV-görünür bölge absorpsiyon, durgun-hal ve zamana bağlı floresans spektroskopisi teknikleri kullanılarak belirlenmiştir. Absorpsiyon spektrumunda literatürde belirtilen dalgaboyunda $(280 \mathrm{~nm})$ pik gözlenmiştir. Farklı dalgaboylarında uyarma yapılarak floresans ölçümleri alınmış ve numunenin floresans bant maksimumunun ve şiddetinin uyarma dalgaboyuna bağlı olarak değiştiği belirlenmiştir. Karbon kuantum nokta numunesi için floresans kuantum verimi ve yașam ömrü gibi fotofiziksel parametreler de hesaplanmıştır. Daha sonra kuantum nokta numunelerinin absorpsiyon ve floresans spektrumlarına konsantrasyonun etkisi incelenmiştir. En iyi çözelti konsantrasyonunun 250 $\mu \mathrm{l}$ karbon nokta/4950 $\mu \mathrm{l}$ saf su karışımı olduğu bulunmuștur.

$\mathrm{Bu}$ konsantrasyon kullanılarak numunenin fotofiziksel özellikleri üzerine $\mathrm{pH}$ ve sıcaklı̆̆ın etkisi incelenmiştir. $\mathrm{pH}=2-14$ aralığında ölçümler alınmış ve $\mathrm{pH}$ değeri arttıkça kuantum nokta çözeltisinin hem absorpsiyon hem de floresans şiddetinin düștüğü belirlenmiștir. Fizyolojik pH'ya yakın değerlerde yüksek floresans özellik göstermesi, elde edilen bu kuantum noktanın biyo-görüntüleme alanında kullanılabileceğinin göstergesi olmuştur. Ayrıca ortam sıcaklığı arttıkça absorpsiyon spektrumunda çok az değişimlerin olması bu numunenin oldukça geniş sıcaklık aralıklarında kullanılabilirliğini göstermiștir. Elde edilen kuantum noktaların kararlılı̆̆ını belirlemek amacıyla örnekler 3 ay süreyle soğuk ortamda bekletilmiş ve sürenin sonunda absorpsiyon ve floresans ölçümleri alınmıştır. Ölçüm sonuçları, ilk elde edildiği zaman alınan sonuçlarla kıyaslandığında değişimin çok az olması bu numunelerin oldukça uzun süre kararlılı̆̆ını koruduğunu kanıtlamıștır. Tüm sonuçlar, kırmızı soğandan elde edilen bu yeni karbon kuantum nokta örneklerinin biyokimyasal, optoelektronik, nanoteknoloji gibi birçok çalıșma alanına önemli katkılar sağlayacağı düşüncesi oluşturmuştur.

\section{Kaynakça}

[1] Gonçalves, H. M. R. 2013. Analytical Applications of Fluorescent Carbon Dots. Doktora Tezi, Faculdade De Ciencias Da Universidade Do Porto, Maio.

[2] Xu, X., Ray, R., Gu, Y., Ploehn, H. J., Gearheart, L., Raker, K., Scrivens, W. A. 2004. Electrophoretic analysis and purification of fluorescent singlewalled carbon nanotube fragments, J. Am. Chem. Soc., 126 (40), 12736-12737.

[3] Sun, Y. P., Zhou, B., Lin, Y., Wang, W., Fernando, K. A., Pathak, P., Meziani, M. J., Harruff, B. A., Wang, X., Wang, H., Luo, P. G., Yang, H., Kose, M. E., Chen, B., Veca, L. M., Xie, S. Y. 2006. Quantum-sized carbon dots for bright and colorful photoluminescence, J. Am. Chem. Soc., 128 (24), 7756-7757.

[4] Wang, Y., Hu, A. 2014. Carbon quantum dots: synthesis, properties and applications, J. Mater. Chem. C 2 (34), 6921-6139.

[5] Lu, W., Qin, X., Liu, S., Chang, G., Zhang, Y., Luo, Y., Asiri, A. M., Al-Youbi, A. O., Sun, X. 2012. Economical, Green Synthesis of Fluorescent Carbon Nanoparticles and Their Use as Probes for Sensitive and Selective Detection of Mercury(II) Ions, Anal. Chem., 84 (12), 53515357.

[6] Wang, L., Zhu, S. J., Wang, H. Y., Qu, S. N., Zhang, Y. L., Zhang, J. H., Chen, Q. D., Xu, H. L., Han, W., Yang, B. Sun, H. B., 2014. Common Origin of Green Luminescence in Carbon Nanodots and Graphene Quantum Dots, ACS Nano, 8 (3), 2541-2547.

[7] Huang, H., Lv, J. J., Zhou, D. L., Bao, N., Xu, Y., Wang, A. J., Feng, J. J., 2013. One-pot green synthesis of nitrogen-doped carbon nanoparticles as fluorescent probes for mercury ions, RSC Adv., 3 (44), 21691-21696.

[8] Luo, P., Li, C., Shi, G. 2012. Synthesis of gold@carbon dots composite nanoparticles for surface enhanced Raman scattering, Phys. Chem. Chem. Phys., 14 (20), 7360-7366. 
[9] Qu, S. N., Wang, X. Y., Lu, Q. P., Liu, X. Y., Wang, L. J. 2012. A Biocompatible Fluorescent Ink Based on Water-Soluble Luminescent Carbon Nanodots, Angew. Chem., Int. Ed., 51 (49), 12215-12218.

[10] Wang, F., Chen, Y. H., Liu, C. Y., Ma, D. G. 2011. White Light- Emitting Devices Based on Carbon Dots' Electroluminescence, Chem. Commun., 47 (12), 3502-3504.

[11] Gu, N., Li, Y., Wang, M., Cao, M. 2013. Nano-optoelectronics for biomedicine. ChinSci Bull., 58 (21), 2521-2529.

[12] Feng, X., Jiang, Y., Zhao, J., Miao, M., Cao, S., Fang, J., Shi, L. 2015. Easy synthesis of photoluminescent $\mathrm{N}$-doped carbon dots from winter melon for bio-imaging, RSC Adv., 5 (40), 31250-31254.

[13] Wu, Z. L., Zhang, P., Gao, M. X., Liu, C. F., Wang, W., Leng, F., Huang, C. Z. 2013. One-pot hydrothermal synthesis of highly luminescent nitrogen-doped amphoteric carbon dots for bioimaging from Bombyx mori silk-natural proteins, J. Mater. Chem. B 1 (22), 2868-2873.

[14] Xu, H., Yang, X., Li, G., Zhao, C., Liao, X., 2015. Green Synthesis of Fluorescent Carbon Dots for Selective Detection of Tartrazine in Food Samples, J. Agric. Food Chem., 63 (30), 67076714.

[15] Liu, H., Ye, T., Mao, C. 2007. Fluorescent carbon nanoparticles derived from candle soot, Angew. Chem. Int. Ed., 46 (34), 6473-6475.

[16] Sahu, S., Behera, B., Maiti, T. K., Mohapatra, S. 2012. Simple one-step synthesis of highly luminescent carbon dots from orange juice: application as excellent bio-imaging agents, Chem. Commun., 48 (70), 8835-8837.

[17] Thakur, M., Pandey, S., Mewada, A., Patil, V., Khade, M., Goshi, E., Sharon M. 2014. Antibiotic Conjugated Fluorescent Carbon Dots as a Theranostic Agent for Controlled Drug Release, Bioimaging, and Enhanced Antimicrobial Activity, J. Drug Deliv., 2014, Article ID 282193.

[18] Feng, J., Wang, W. J., Hai, X., Yu, Y. L. Wang, J. H., 2016. Green preparation of nitrogen-doped carbon dots derived from silkworm chrysalis for cell imaging, J. Mater. Chem. B 4 (3), 387-393.

[19] Xue, M., Zhan, Z., Zou, M., Zhang, L., Zhao, S. 2016. Green synthesis of stable and biocompatible fluorescent carbon dots from peanut shells for multicolor living cell imaging, New J. Chem., 40 (2), 1698-1703.

[20] Liang, Q., Ma, W., Shi, Y., Li, Z. Yang, X. 2013. Easy synthesis of highly fluorescent carbon quantum dots from gelatin and their luminescent properties and applications, Carbon, 60, 421-428.
[21] Yang, X., Zhou, Y., Zhu, S.H., Luo, Y., Feng, Y., Dou, Y. 2014. Novel and green synthesis of highfluorescent carbon dots originated from honey for sensing and imaging, Biosensors and Bioelectronics, 60, 292-298.

[22] Zhou, H. S., Wang, L. 2014. Green Synthesis of Luminescent Nitrogen-Doped Carbon Dots from Milk and Its Imaging Application, Anal. Chem, dx.doi.org/10.1021/ac502646x.

[23] Zhu, C., Zhai, J., Dong, S. 2012. Bifunctional fluorescent carbon nanodots: green synthesis via soy milk and application as metal-free electrocatalysts for oxygen reduction, Chem. Commun., 48 (75) , 9367-9369.

[24] Zheng, H., Wang, Q., Long, Y., Zhang, L., Gao, M., Bai, W. 2011. Microwave-hydrothermal synthesis of fluorescent carbon dots from graphite oxide, Carbon, 49, 3134-3140.

[25] Yang, Z., Li, Z., Xu, M., Ma, Y., Zhang, J., Su, Y., Gao, F., Wei, H., Zhang, L. 2013. Controllable Synthesis of Fluorescent Carbon Dots and Their Detection Application as Nanoprobes. Nano-Micro Lett. 5 (4), 247-259.

[26] Prasannan, A., Imae, T. 2013. One-Pot Synthesis of Fluorescent Carbon Dots from Orange Waste Peels, Ind. Eng. Chem. Res. 2013, 52 (44), 1567315678.

[27] Lim, S. Y., Shen, W., Gao, Z. 2015. Carbon quantum dots and their applications, Chem. Soc. Rev., 44 (1), 362-381.

[28] Liu, S., Tian, J., Wang, L., Zhang, Y., Qin, X., Luo, Y., Asiri A.M., Al-Youbi A.O., Sun, X. 2012. Hydrothermal treatment of grass: a low-cost, green route to nitrogen-doped, carbon-rich, photoluminescent polymer nanodots as an effective fluorescent sensing platform for labelfree detection of $\mathrm{Cu}(\mathrm{II})$ ions. Adv Mater., 24 (15), 2037-2041.

[29] Biçer, K. B. 2017. Karbon Kuantum Noktaların Sentezive Fotolüminesans Özelliklerinin İncelenmesi, Atatürk Üniversitesi Fen Bilimleri Enstitüsü, Yüksek Lisans Tezi, 41 s, Erzurum.

[30] Melis Özge Alaş, Rükan Genç, 2016, "Floresans Karbon Nanoparçacıkların Yeşil Sentezi ve Pasivasyon Ajanının Molekül Ağırlığının Nanoparçacık Özellikleri Üzerine Etkisinin İncelenmesi", Sinop Üniversitesi Fen Bilimleri Dergisi (Sinop Uni J Nat Sci), 1 (2), 123-134.

[31] Bozkurt, E. 2013. Kumarin 120 Boya Bileșiğinin Ters Misellerde Moleküler Davranışının Spektroskopik Tekniklerle İncelenmesi, Atatürk Üniversitesi Fen Bilimleri Enstitüsü, Doktora Tezi, 118 s, Erzurum. 
[32] Terzi, P. 2013. Elektro döndürme Yöntemiyle Elde Edilen Jelatin Nanoliflerin Gidalarda Kıvam Verici Olarak Kullanılması, İstanbul Teknik Üniversitesi, Gıda Mühendisliği Anabilim Dalı, Yüksek Lisans Tezi, $143 \mathrm{~s}$, İstanbul.

[33] Hsiao Wei, T., 2009. Rhelogy And Stability of Olive Oil Cream Emulsion Stabilized by Sucrose Fatty Acid Esters Nanionic Surfactans, Malaya Kuala Lumpur Üniversitesi, Yüksek Lisans Tezi, 62s, Malezya.
[34] Yu, S. J., Kang, M. W., Chang, H. C., Chen, K. M., Yu, Y. C., 2005. Bright fluorescent nanodiamonds: No photobleaching and low cytotoxicity, J. Am. Chem. Soc., 127, 17604-17605.

[35] Aslandaş, A. M., Balcı, N., Arık, M., Şakiroğlu, H., Onganer, Y., Meral, K. 2015. Liquid nitrogenassisted synthesis of fluorescent carbon dots from Blueberry and their performance in $\mathrm{Fe} 3+$ detection, Applied Surface Science, 356, 747-752. 